\title{
A novel, multiplex, real-time PCR-based approach for the detection of the commonly occurring pathogenic fungi and bacteria
}

\author{
Ádám Horváth ${ }^{1 *}$, Zoltán Pető ${ }^{2 \dagger}$, Edit Urbán ${ }^{3 \dagger}$, Csaba Vágvölgyi $^{4 \dagger}$ and Ferenc Somogyvári ${ }^{1 \dagger}$
}

\begin{abstract}
Background: Polymerase chain reaction (PCR)-based techniques are widely used to identify fungal and bacterial infections. There have been numerous reports of different, new, real-time PCR-based pathogen identification methods although the clinical practicability of such techniques is not yet fully clarified.

The present study focuses on a novel, multiplex, real-time PCR-based pathogen identification system developed for rapid differentiation of the commonly occurring bacterial and fungal causative pathogens of bloodstream infections.

Results: A multiplex, real-time PCR approach is introduced for the detection and differentiation of fungi, Gram-positive $(\mathrm{G}+)$ and Gram-negative (G-) bacteria. The Gram classification is performed with the specific fluorescence resonance energy transfer (FRET) probes recommended for LightCycler capillary real-time PCR. The novelty of our system is the use of a non-specific SYBR Green dye instead of labelled anchor probes or primers, to excite the acceptor dyes on the FRET probes. In conjunction with this, the use of an intercalating dye allows the detection of fungal amplicons. With the novel pathogen detection system, fungi, G + and G- bacteria in the same reaction tube can be differentiated within an hour after the DNA preparation via the melting temperatures of the amplicons and probes in the same tube.

Conclusions: This modified FRET technique is specific and more rapid than the gold-standard culture-based methods. The fact that fungi, G + and G- bacteria were successfully identified in the same tube within an hour after the DNA preparation permits rapid and early evidence-based management of bloodstream infections in clinical practice.
\end{abstract}

Keywords: Clinically relevant bacteria, Candida, Melting point analysis, Fluorescence resonance energy transfer, Bloodstream infections

\section{Background}

Bloodstream infections are life-threatening, especially in individuals with serious underlying conditions or an impaired immune system [1]. The number of reported cases of bloodstream infections in the USA, between 1979 and 2002, was 10, 319, 418 and demonstrated an annualized increase of $8.7 \%$ [2]. In critically ill patients, the majority of infections are caused by bacteria but fungal infections, although these account for only $4.6 \%$ of all infections, have a significant impact on public health. [2]. Mixed fungal/bacterial infections are not uncommon,

\footnotetext{
* Correspondence: horvath.adam.1@med.u-szeged.hu

${ }^{\dagger}$ Equal contributors

'Department of Medical Microbiology and Immunobiology, Faculty of Medicine, University of Szeged, Dóm tér 10, Szeged H-6720, Hungary Full list of author information is available at the end of the article
}

incidences of combined Candida and bacterial bloodstream infections have been reported in as many as $23 \%$ of all episodes of candidaemia [3]. Despite its relatively low frequency, fungal blood stream infections can progress to severe sepsis and septic shock, associated with a drastic rise in mortality; therefore, early and appropriate treatment of such infections is critical $[4,5]$.

Since molecular diagnosis in sepsis is reliable, and faster than the classical blood-culturing techniques, there has been an increase in interest in methods such as PCR, ligase chain reaction, nucleic acid sequence based amplification, and nested PCR [6,7]. Nevertheless, these molecular approaches are applied only following the positivity of the blood culture; therefore, they require a substantial amount of elapsed time.

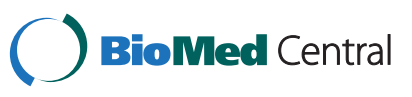

(c) 2013 Horváth et al.; licensee BioMed Central Ltd. This is an open access article distributed under the terms of the Creative Commons Attribution License (http://creativecommons.org/licenses/by/2.0), which permits unrestricted use, distribution, and reproduction in any medium, provided the original work is properly cited. 
In contrast, the LightCycler PCR assay is fast, reliable and relatively easy to perform - even in small laboratories.

This method is based on a previously-reported fluorescence resonance energy transfer (FRET) technique which involves a distance-dependent interaction between the electronic excited states of two dye molecules [8]. The excitation is transferred from a donor (anchor) molecule to an acceptor (quencher) molecule, without emission of a photon, and has been proved to be an appropriate method for discriminating between the commonly occurring pathogen $\mathrm{G}+$ and G- bacteria [9]. The differentiation, via the melting temperature of the overall PCR product and the melting point of the probes, allowed creation subgroups within the G+and G- stains, and this system required less than $4 \mathrm{~h}$, inclusive of the time need for the DNA preparation and the evaluation of the PCR results [10]. Until now, parallel detection of fungal and bacterial infections in a real-time system has been an unresolved problem however there are several tests in the market with the same purpose. Some of them detect bacteria, without fungal identification (Prove-It; Mobidiag, Helsinki, Finland or SeptiTest; Molzym, Bremen, Germany). The Reflex PCR assay (Molzym, Bremen, Germany) includes several steps after the PCR which increases the time required. The SepiFast (Roche; Basel, Switzerland) assay is similar to our system but works with three parallel reaction vessels and a different principle for detection. Furthermore, it requires individual molecular laboratory, equipments and software. Identification of the most common clinically relevant fungi is possible through a simple meltingpoint analysis relating to the ITS2 (internal transcribed spacer) region. This non-coding region is a highly variable rRNA region that is adaptable for the identification of clinically relevant fungi over a broad range [11]. Measurements are made at $540 \mathrm{~nm}$, and require a non-specific intercalating dye [12].

Real-time PCR detection can be performed by using free dyes or labelled sequence-specific probes. One combination of the two techniques uses unlabelled probes for the amplicon detection and $T_{m}$ determination [13]. Another parallel application was the combination of TaqMan chemistry and the very new, aspecific dye, BOXTO, as a multiplex PCR [14].

The novelty of our prototype system lies in the use of non-specific SYBR Green dye as a donor molecule, instead of a labelled primer or other specific anchor probe. With this technique, it is possible to examine pathogenic fungi, G + and G- bacteria in a single tube multiplex PCR reaction.

\section{Results and discussion}

Discrimination of the fungal, G + and G- bacterial pathogens DNA samples from all species studied were prepared and amplified successfully with the SYBR Green dye-based method in the LightCycler instrument. Species-specific $\mathrm{T}_{\mathrm{m}}$-s were obtained by melting-point analysis on three detection channels and all pathogens were identified correctly as fungi or G- or G + bacteria (Table 1). On the F1 channel $(540 \mathrm{~nm})$, the melting points of all the amplicons $\left(\mathrm{T}_{\mathrm{m}} \mathrm{A}\right)$ were visible, due to the fluorescent signal of the SYBR Green non-specific intercalating dye. On the F2 $(640 \mathrm{~nm})$ and F3 $(705 \mathrm{~nm})$ channels, the $\mathrm{G}$ - and the $\mathrm{G}+$ probes $\left(\mathrm{T}_{\mathrm{m}} \mathrm{P}\right)$, respectively, gave fluorescence signals. After the discrimination of the G- and G + strains, the fungal pathogens could be screened, because the fungal strains gave no signal on the F2; F3 channels.

Table 1 Melting points of bacterial and fungal amplicons and probes

\begin{tabular}{|c|c|c|c|c|}
\hline \multirow{2}{*}{$\begin{array}{l}\text { Microbial strains } \\
\text { Gram positive (G+) }\end{array}$} & \multicolumn{2}{|c|}{$\begin{array}{c}T_{m} P \\
\left({ }^{\circ} \mathrm{C}\right)\end{array}$} & \multicolumn{2}{|c|}{$\begin{array}{c}\mathrm{T}_{\mathrm{m}} \mathrm{A} \\
\left({ }^{\circ} \mathrm{C}\right)\end{array}$} \\
\hline & Mean & SD & Mean & SD \\
\hline Enterococcus faecalis & 67.94 & 0.07 & 84.14 & 0.36 \\
\hline Enterococcus faecium & 67.84 & 0.21 & 84.59 & 0.78 \\
\hline Listeria monocytogenes & 67.80 & 0.19 & 86.01 & 0.36 \\
\hline Staphyloccus aureus & 64.85 & 0.21 & 83.91 & 0.54 \\
\hline Staphyloccus epidermidis & 64.50 & 0.30 & 83.60 & 0.36 \\
\hline Streptococcus pyogenes & 46.54 & 0.56 & 84.38 & 0.78 \\
\hline \multicolumn{5}{|l|}{ Gram negative (G-) } \\
\hline Acinetobacter baumannii & 66.09 & 0.15 & 82.90 & 0.16 \\
\hline Bacteroides fragilis & 48.65 & 0.18 & 84.47 & 0.84 \\
\hline Enterobacter aerogenes & 63.95 & 0.34 & 83.47 & 0.48 \\
\hline Enterobacter cloacae & 64.98 & 0.09 & 84.38 & 0.24 \\
\hline Escherichia coli & 64.69 & 0.44 & 84.74 & 0.54 \\
\hline Haemophilus influenzae & 61.99 & 0.35 & 84.28 & 0.30 \\
\hline Klebsiella pneumoniae & 65.13 & 0.23 & 84.57 & 0.20 \\
\hline Proteus vulgaris & 64.58 & 0.18 & 82.87 & 0.24 \\
\hline Pseudomonas aeruginosa & 53.32 & 0.33 & 83.00 & 0.34 \\
\hline Serratia marcescens & 64.01 & 0.30 & 84.17 & 0.30 \\
\hline Stenotrophomonas maltophilia & 58.10 & 0.07 & 84.42 & 0.15 \\
\hline \multicolumn{5}{|l|}{ Fungi } \\
\hline Candida albicans & - & - & 87.1 & 0.33 \\
\hline Candida dubliniensis & - & - & 85.5 & 0.50 \\
\hline Candida quillermondii & - & - & 85.1 & 0.70 \\
\hline Candida krusei & - & - & 89.8 & 0.02 \\
\hline Candida parapsilosis & - & - & 85.4 & 0.88 \\
\hline Candida tropicalis & - & - & 84.5 & 0.75 \\
\hline Aspergillus fumigatus & - & - & 91.0 & 0.38 \\
\hline
\end{tabular}

All the amplicons $T_{m}$ were measured at the $F 1$ channel $(540 \mathrm{~nm})$. The signal was generated by aspecific SybrGreen dye. The $G+$ specific probes produced a signal at the F2 channel $(640 \mathrm{~nm})$ the $\mathrm{G}$ - probes at the F3 channel $(705 \mathrm{~nm})$. The signals were induced with the help of a special FRET technique. 


\section{Determination of the bacterial pathogens}

Four G + and nine G- bacterial subgroups could be distinguished through a joint consideration of the melting points of the probes and the melting point of the overall PCR product (Figure 1).

S. aureus and S. epidermidis have very close-lying melting temperatures and their species-specific differentiation is not possible via this 16S rRNA sequence (Figure 2). A comparison of the Gene Bank sequences (S. aureus and S. epidermidis NCBI Taxonomy ID: NC_009782.1 and JF_799903.1) of these species revealed a variance of only three base-pairs, none of them in the region where the probe is associated with the DNA. Thus, determination of the clinically relevant Staphylococcus species requires other gene sequences in which the antibiotic resistance can be detected [15]. The situation is the same for the two Enterococcus species [16]. At the same time, S. pyogenes and $L$. monocytogenes are clearly differentiable.

Among the G- bacteria, E. coli is one of the most common causative agents of bloodstream infections [17]. Unfortunately, it has almost the same $\mathrm{T}_{\mathrm{m}}$ as those of $E$. cloacae and S. marcescens. Other bacterial strains, such as $H$. influenza, are clearly differentiable through the melting temperature of the probe (Figure 3) or amplicon. The sensitivity of the reaction was five colonyforming units (CFU) per reaction.

\section{Determination of fungal pathogens}

Fourteen frequently-encountered fungal pathogens could be distinguished. The highly variable ITS 2 target sequence allowed correct identification of all of the clinically relevant fungal strains, through the $\mathrm{T}_{\mathrm{m}}$ points on the $\mathrm{F} 1$ channel $[12,18]$. There was no signal on the F2 or F3 channel. The sensitivity of the reaction was $5 \mathrm{CFU}$ per reaction.

The correct differentiation between bacteria and fungi was verified by means of gel electrophoresis, with the help of the amplicon length (fungal amplicons 192$494 \mathrm{bp}$, bacterial $187 \mathrm{bp}$ ).

\section{Determination of the co-infection model}

In case of co-infections, there are some limitations in the detection. If the ratios of the different agents are higher than 1:10, the system does not detect the infectious agent which is in lower quantities.

\section{Calibration of the multiplex PCR}

All three non-specific dyes (LCGreen, EvaGreen and SybrGreen) excited all of the labelled probes (LCRed640, LCRed705 and Cy5.5). The best results were obtained with the SybrGreen dye.

The determination of $T_{m}$ is very sensitive to the composition of the PCR reaction mixture, and primarily to the ionic strength. To avoid $\mathrm{T}_{\mathrm{m}}$ bias originating from pipetting errors between PCR runs, the application of mastermixes is advisable. One limitation of the method is that the various mastermixes offered by different suppliers differ in reagent composition, which may influence the $\mathrm{T}_{\mathrm{m}}$ values.

Naturally, repeated runs with a given mastermix yield reproducible data. In the event of a change of mastermix, however, calibration is necessary to establish the new $\mathrm{T}_{\mathrm{m}}$ data on the fungal strains.
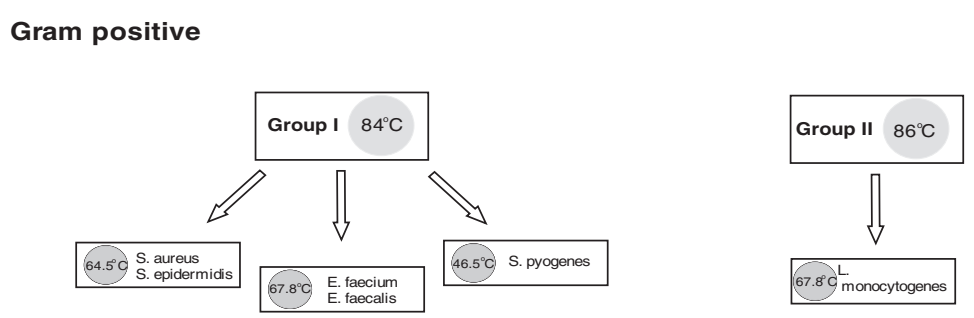

Gram negative

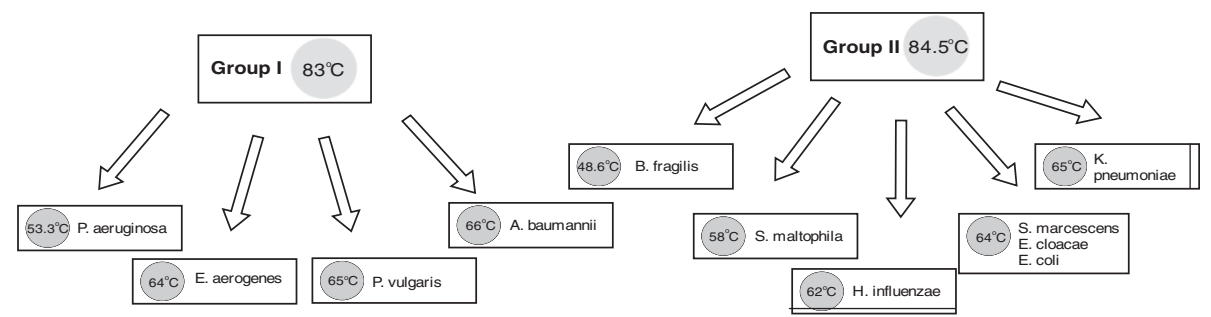

Figure 1 Differentiation of the bacterial pathogens. The group temperatures indicate the entire $T_{m}$ of the pathogens. The subgroup temperatures are the melting temperatures of the hybridization probes. 


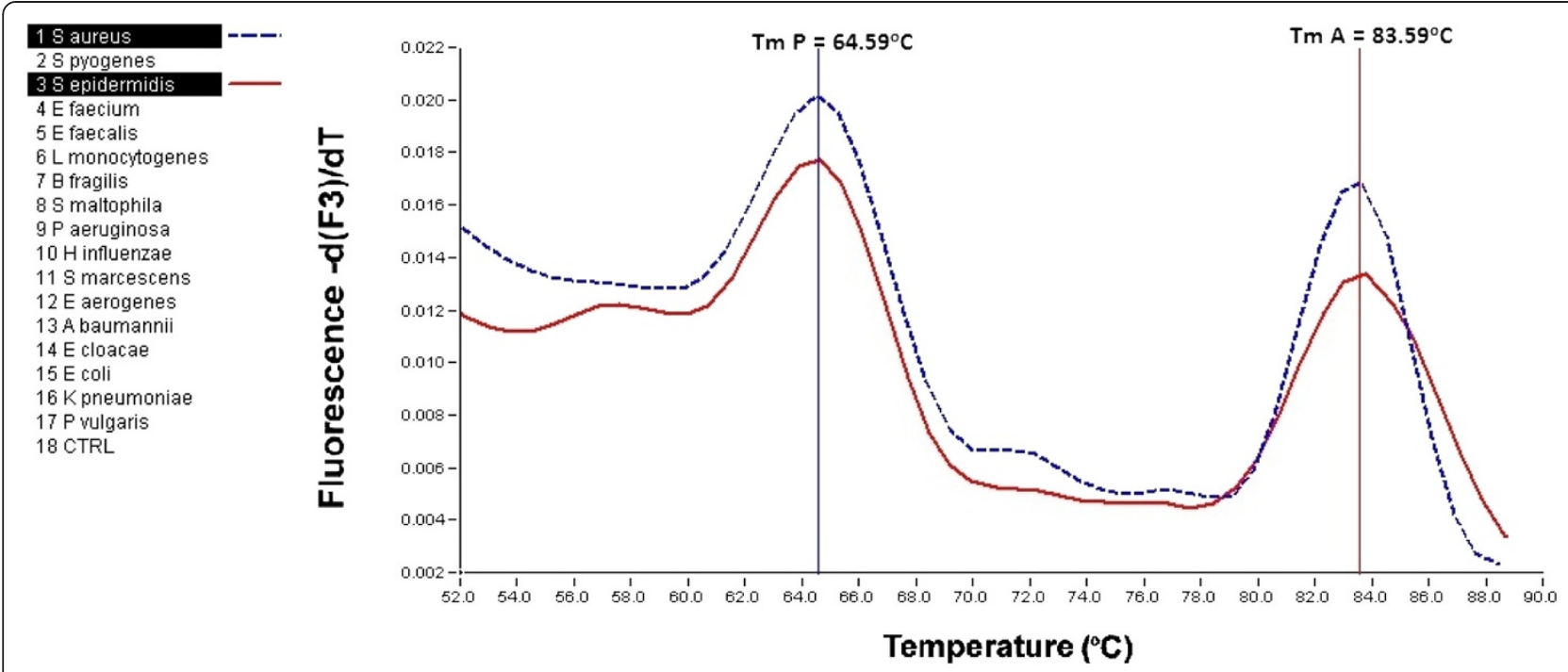

Figure 2 Melting-peaks of Staphylococcus aureus and Staphylococcus epidermidis. Revealing that it is impossible to differentiate these Staphylococcus species via the $T_{m}$ data of the amplicons or probes.

The data determined in the present work were obtained with the use of "Fermentas Maxima SybrGreen, no ROX" and five-eight parallel experiments. No false positive samples were found when this method was tested. No significant differences in the melting peak temperatures were observed between different isolates of the same species. The standard deviation of the melting peak temperatures of all 21 references and 93 clinical isolates with bacterial and fungal strains was between 0.08 and 0.88 , as listed in Table 1. These data are in concordance with our previous results $[19,20]$.

\section{Sensitivity and reproducibility}

For sensitivity testing of the prototype system, six bacterial and two fungal gDNA preparations were made from artificially infected blood. Eight species, and eight parallel investigations of five dilutions of the bacterial suspensions in blood were, analysed. Of 8 reactions for each species, all were positive with 50 DNA copies, $98.5 \%$ were positive with 10 copies, $67.2 \%$ were positive with 5 copies and $21.9 \%$ were positive with 2 copies (Table 2). All the reactions were carried out within the same parameters described in the section PCR conditions.

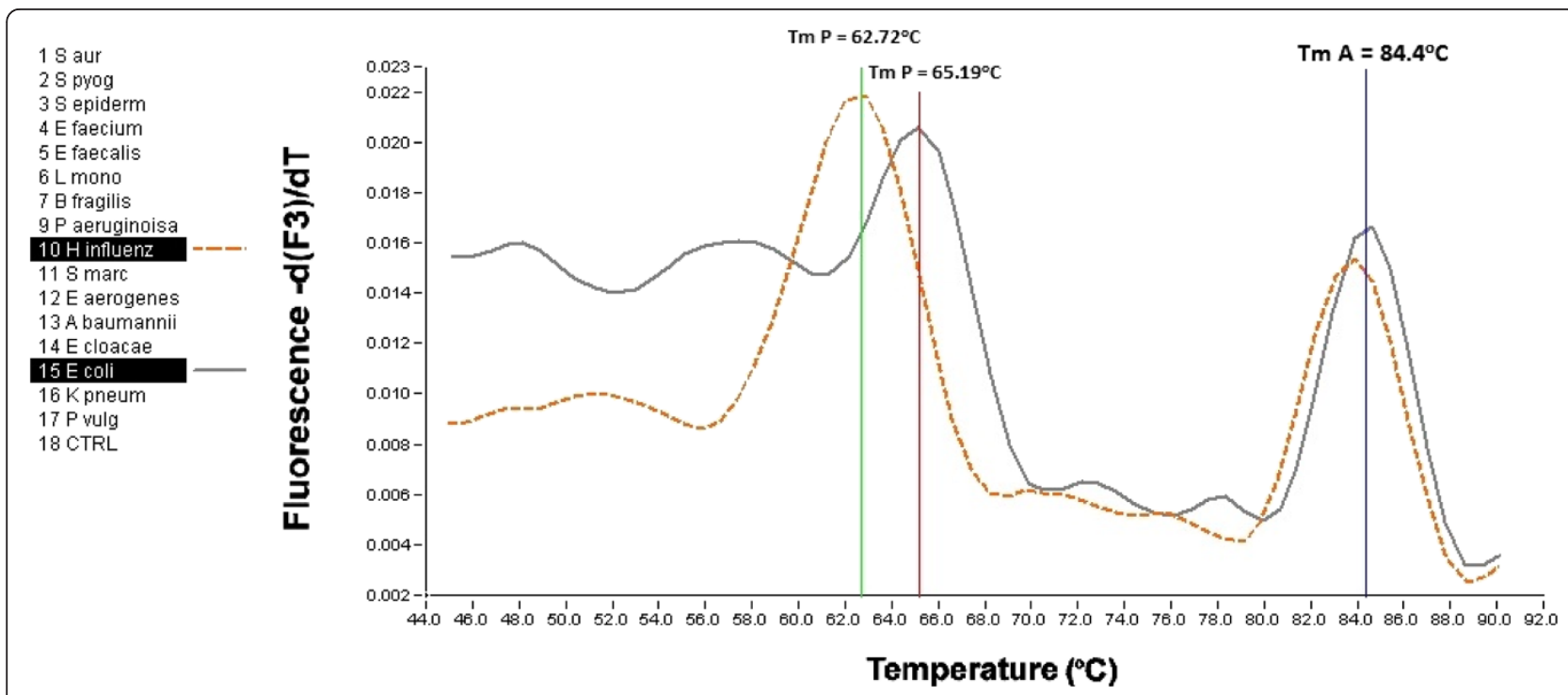

Figure 3 Differentiation of Escherichia coli from Haemophilus influenzae. Although these pathogens have a very similar $T_{m}$ in the 165 rRNA region, the $T_{m}$ of the probes are clearly different. 
Table 2 Diagnostic sensitivity of the PCR

\begin{tabular}{lcccccc}
\hline \multicolumn{1}{c}{ Microbial strains } & \multicolumn{5}{c}{ No. (\%) of positive PCRs* } \\
\hline Gram positive (G+) & 50 copies & 10 copies & 5 copies & 2 copies & 1 copy \\
Enterococcus faecalis & $8(100)$ & $8(100)$ & $5(62.5)$ & $2(25)$ & $0(0)$ \\
Staphylococcus aureus & $8(100)$ & $8(100)$ & $7(87.5)$ & $3(37.5)$ & $0(0)$ \\
Streptococcus pyogenes & $8(100)$ & $8(100)$ & $5(62.5)$ & $5(62.5)$ & $0(0)$ \\
Gram negative (G-) & & & & & \\
Enterobacter aerogenes & $8(100)$ & $8(100)$ & $5(62.5)$ & $2(25)$ & $0(0)$ \\
Escherichia coli & $8(100)$ & $8(100)$ & $6(75)$ & $1(12.5)$ & $0(0)$ \\
Haemphilus influenzae & $8(100)$ & $7(87.5)$ & $4(50)$ & $0(0)$ & $0(0)$ \\
Fungi & & & & & \\
Candida albicans & $8(100)$ & $8(100)$ & $5(62.5)$ & $0(0)$ & $0(0)$ \\
Candida tropicalis & $8(100)$ & $8(100)$ & $6(75)$ & $1(12.5)$ & $0(0)$ \\
\hline
\end{tabular}

*Out of 8 samples.

Three Gram positive, three Gram negative and two fungal strains were used for the infection of healthy donor bloods. All the experiments were carried out eight times using 5 dilutions of the pathogens.

\section{Conclusions}

Real-time PCR is one of the fastest diagnostic methods currently available. The use of rRNA genes for the detection is based on the conserved 16S rRNA sequences of the bacteria. As regards fungi, the ITS sequence refers to a segment of non-functional RNA, situated between $5.8 \mathrm{~S}$ and $28 \mathrm{~S}$ rRNAs. To reproduce the results, it is possible to differentiate between fungi and bacteria, or between fungal species by electrophoresis [21,22] or melting-point analysis [23]. The Roche LightCycler PCR was specially developed to amplify amplicons under $500 \mathrm{bp}$. The amplicons amplified by PLK1/PLK2 comprised $187 \mathrm{bp}$, while the fungal amplicons amplified by ITS86/ITS4 primer pair varied between 192 bp (Geotrichum candidum) and 494 bp (Malassezia furfur), values which are perfectly suited to this instrument profile. In this study, the advantage of the LC system was utilised when FRET technique was used to detect and differentiate the bacterial pathogens. As a novel element, excitation of the fluorescent probes was carried out with the help of a non-specific intercalating dye, this is an uncommon procedure in real-time investigations. It allows parallel detection of fungal pathogens and with bacteria in the same tube. As the result of the use of the multiplex PCR in combination with FRET probes and melting point-analysis, the broad-range identification of many frequent causative agents of bloodstream infections becomes possible within four hours. Sensitivity of pathogen PCR in sepsis is generally between 3 and $100 \mathrm{CFU} / \mathrm{mL}$ according to the literature [24]. The sensitivity of our prototype system was five CFU per reaction, which in combination with an efficient preparation is suitable for the detection of bloodstream infections. If commercially available "Midi" preparation kits (i.e.: NucleoSpin Blood L,
Macherey-Nagel, Düren, Germany) were used, the sample mateial was $2 \mathrm{~mL}$ of blood, the elution volume was $100 \mu \mathrm{L}$ and finally $5 \mu \mathrm{L}$ of eluate were used for subsequent PCR. The calculated sensitivity was $50 \mathrm{CFU} / \mathrm{mL}$ blood. The sample/eluent ratio was the same in case of midi and maxi preparation kits which means that increased sample volume is not enhancing the sensitivity [25]. The sensitivity of the "gold standard" conventional blood culture technique is one CFU per $10 \mathrm{~mL}$ blood sample. Our method is less sensitive. The blood culture technique is not replaceable with molecular techniques so far but the time delay until the adequate therapy can be reduce.

To determine the diagnostic sensitivity and reproducibility of the method, experiments with artificially infected blood were performed. The sensitivity of the PCR was 2 to 10 copies per reaction, which was the same as with cultivated cells. The melting points (TmA and TmP) were the same as we described in Table 1. with "Fermentas Maxima SybrGreen, no ROX"; therefore, human gDNA does not inhibit the reaction and does not modify the melting peaks.

With this method, neither the $G+S$. aureus and $S$. epidermidis nor the G- E. coli, E. cloacae and S. marcescens can be distinguished, and additional species-specific probes or primers are necessary for the further differentiation of these species.

Antibiotic resistance cannot be determined directly with this prototype system. The susceptibility testing of resistant E. coli strains can be performed using a PCR-based technique with other 16S rRNA specific primers [26]. Unfortunately, these investigations require a PCR analysis after the identification of the bacteria.

In spite of its limitations, the prompt and reliable information provided by this new diagnostic method on the most common pathogenic bacteria might permit targeted therapy with narrow-spectrum antibiotics, instead of empirically-administered broad-spectrum antibiotics. To confirm these findings in clinical practice, a prospective study is now being designed and engineered.

The incidence of sepsis has been continuously increasing over recent decades, and the early detection of the pathogens can have a great impact on the clinical outcome of infections [27-30] Molecular diagnostic systems allow species identification in less than 24 hours - which is a drastic improvement relative to the gold-standard, culturebased method and Gram staining-based identification methods that yield results in 24 to 72 hours $[31,32]$.

With the novel method described above (multiplex PCR with the new combination of aspecific dyes and labelled probes), the most common causative agents of bloodstream infections can be detected in two hours, without DNA preparation; therefore, this method offers a huge advantage over traditional FRET-based assays by accurately detecting the $\mathrm{T}_{\mathrm{m}}$ of both the probes and the amplicons. 


\section{Methods}

Reference strains of 17 clinically relevant bacterial species were collected, as typical of the main causative agents of bloodstream infections [33]. Nine reference strains, Staphylococcus aureus ATCC 25923, Staphylococcus epidermidis ATCC 12228, Enterococcus faecalis ATCC29212, Listeria monocytogenes ATCC 4701, Bacteroides fragilis ATCC 25285, Pseudomonas aeruginosa ATCC 27853, Haemophilus influenzae ATCC 49247, Escherichia coli ATCC 25922 and Klebsiella pneumoniae ATCC 700603 were from the American Type Culture Collection. [ATCC]. Streptococcus pyogenes OKI 80002 was from the National Centre for Epidemiology, Hungary [OKI] and Proteus vulgaris HNCMB 60076 was from the Hungarian National Collection of Medical Bacteria [HNCMB]. Furthermore, to confirm the reliability and reproducibility of the technique, clinical strains of $S$. aureus $(\mathrm{n}=4), S$. epidermidis $(\mathrm{n}=6)$, S. pyogenes $(\mathrm{n}=2)$, E. faecalis $(\mathrm{n}=2)$, E. faecium $(\mathrm{n}=3)$, L. monocytogenes $(\mathrm{n}=1)$, B. fragilis $(\mathrm{n}=2), P$. aeruginosa $(\mathrm{n}=1), H$. influenzae $(\mathrm{n}=1), E$. coli $(\mathrm{n}=5), K$. pneumoniae $(\mathrm{n}=5)$, P. vulgaris $(\mathrm{n}=3)$, Stenotrophomonas maltophilia $(\mathrm{n}=2)$, Serratia marcescens $(\mathrm{n}=2)$, Enterobacter aerogenes $(\mathrm{n}=2)$, E. cloacae $(\mathrm{n}=2)$ and Acinetobacter baumannii $(\mathrm{n}=3)$ from the Institute of Clinical Microbiology at the University of Szeged were also included. The species identities of the clinical isolates were confirmed by conventional biochemical methods.

Ten fungal strains were examined. Five reference strains, Candida albicans ATCC 10231 and ATCC 14053, C. tropicalis ATCC 750, C. parapsilosis ATCC 22019 and C. glabrata ATCC 39316, were from the [ATCC], Cryptococcus neoformans IFM 5844 and IFM 5855 were from IFM Quality Services Pty Ltd [IFM], and Aspergillus fumigatus SzMC 2486, A. flavus SzMC 2536 and A. niger SzMC 2761 were from the Szeged Microbiological Collection [SzMC]. Furthermore, clinical strains of C. albicans $(\mathrm{n}=14), C$. glabrata $(\mathrm{n}=5), C$. tropicalis $(\mathrm{n}=4), C$. parapsilosis $(\mathrm{n}=5)$, C. krusei $(\mathrm{n}=4)$, C. quillermondii $(\mathrm{n}=4)$, C. lusitaniae $(\mathrm{n}=3), C$. norvegensis $(\mathrm{n}=1), C$. inconspicua $(\mathrm{n}=2)$, C. dubliniensis $(\mathrm{n}=2)$ and Cryptococcus neoformans $(\mathrm{n}=2)$ from the Institute of Clinical Microbiology at the University of Szeged were also tested.

\section{Bacterial DNA purification}

The bacterial strains were grown on Columbia agar base under aerobic conditions, except that Bacteroides fragilis was grown under anaerobic conditions. The bacterial DNA was extracted with the QIAamp ${ }^{\bullet}$ DNA Blood Mini Kit (QuiaGene Inc, Chatsworth, Calif., USA), following the manufacturer's instructions in "Protocols for Bacteria". One millilitre of log-phase culture suspension, at a concentration of $10^{7} \mathrm{CFU} / \mathrm{mL}$, was used for the preparation. For determination of the sensitivity of the reaction, $100 \mu \mathrm{L}$ of the serially diluted $S$. aureus reference strain was used for DNA extraction. The number of bacterial cells was determined by plating aliquots of serially diluted samples onto Columbia agar base.

For lysis of the rigid multilayered G + bacterial cell wall, we used a pre-incubation step with $20 \mathrm{mg} / \mathrm{mL}$ lysozyme (in $20 \mathrm{mM}$ Tris $\cdot \mathrm{HCl}, \mathrm{pH}$ 8.0, $2 \mathrm{mM}$ EDTA, 1.2\% TritonX100). The spin protocol for "DNA Purification from Tissues" was followed, after incubation at $30^{\circ} \mathrm{C}$ for $30 \mathrm{~min}$. The final concentration of DNA was $2.0-13.8 \mathrm{ng} / \mu \mathrm{L}$, with a ratio A260/A280 = 1.6-1.8 after purification.

\section{Fungal DNA purification}

All the fungi were grown on Sabouraud medium. The fungal DNA was extracted from $1 \mathrm{~mL}$ of a log-phase culture suspension containing $9.6 \times 10^{7}$ of fungal cells. For determination of the sensitivity of the reaction, $100 \mu \mathrm{L}$ of the serially diluted C. albicans reference strain was used for DNA extraction. The number of fungal cells was determined by plating aliquots of serially diluted samples onto Sabouraud-glucose medium.

We followed the QIAamp ${ }^{\bullet}$ DNA Mini Kit Protocol for Yeasts. In this case, additional reagents were required for elimination of the complex fungal cell-wall structure: sorbitol buffer (1 M sorbitol, $100 \mathrm{mM}$ EDTA, $14 \mathrm{mM}$ $\beta$-mercaptoethanol) [34] was used, and the samples were incubated with lyticase for $30 \mathrm{~min}$ at $30^{\circ} \mathrm{C}$. Efficient and complete lysis was achieved in 1.5 hour in a shaking water-bath. This purification yielded $2.0-25 \mu \mathrm{g}$ of DNA in $100 \mu \mathrm{L}$ of water $(2.0-13.8 \mathrm{ng} / \mu \mathrm{L})$, with $\mathrm{A} 260 / \mathrm{A} 280=1.6-1.8$.

\section{DNA preparation from infected blood}

Samples of $180 \mu \mathrm{L}$ healthy donor bloods in EDTA vacutainer tubes were infected with $20 \mu \mathrm{L}$ of log-phase culture suspension at a concentration of $10^{8} \mathrm{CFU} / \mathrm{mL}$ bacterial and/or fungal suspensions. Bacterial and fungal cells were quantified, in a Bürker chamber, by viable counts. For the sensitivity testing of the prototype system, the bloods were infected with five dilutions of the log-phase culture suspension at a final volume of $20 \mu \mathrm{L}$. The first dilution contained 50 copies in $1 \mu \mathrm{L}$ template DNA $\left(2.5 \times 10^{4} \mathrm{CFU} / \mathrm{mL}\right.$ blood $)$, the second contained 10 copies $\left(5 \times 10^{3} \mathrm{CFU} / \mathrm{mL}\right.$ blood), the third 5 copies $\left(2.5 \times 10^{2} \mathrm{CFU} / \mathrm{mL}\right.$ blood) and the fourth 2 copies $\left(5 \times 10^{2}\right.$ $\mathrm{CFU} / \mathrm{mL}$ blood). The red blood cells were disrupted by lysis buffer [35], the bacterial and fungal cell wall lysed using the freezing-thawing method. After digestion with Proteinase $\mathrm{K}$, the DNA was extraction carried out as reported previously [36].

\section{Bacterial and fungal primer design, FRET probes}

Two primer pairs were used for multiplex amplification of bacterial and fungal DNA.

The bacterial primer pair was PLK1 (TAC GGG AGG CAG CAG) forward and PLK2 (TAT TAC CGC GGC 
TGC T) reverse, which are highly conserved in different groups of bacteria [9] and amplify the 16S rRNA sequence. The PLK2 reverse primer was modified and used without the inner fluorescence labelling. Originally, the labelled primer excited the Gram specific probes. We applied the non-specific SYBR Green dye for excitation; it also serves for visualization of the fungal amplicons. This primer-pair produces a $187 \mathrm{bp}$ fragment in each species.

Previously hybridization probes were used for the Gram classification [10]. ISN2 (5'-CCG CAG AAT AAG CAC CGG CTA ACT CCG T-3') labelled with LCRed 640 was specific for G-, and ISP3 (5'-CCT AAC CAG AAA GCC ACG GCT AAC TAC GTG-3') labelled with Cy5.5 was specific for $G+$ bacteria, and the [10] ISP2 probe was labelled with LCRed705 at the $5^{\prime}$ end. The producers offered Cy5.5 dye instead of LCred705. This modified probe was used in our experiments.

The ITS86 forward (GTG AAT CAT CGA ATC TTT GAA C) and the ITS 4 reverse (TCC TCC GCT TAT TGA TAG C) primers were used for detection of the fungi. These primers amplify a 192-494 bp sequence of ITS2 region, which is a highly variable part between the $5.8 \mathrm{~S}$ and $28 \mathrm{~S}$ rRNA sequence [37].

\section{Mastermixes/excitation dyes}

Different, non-specific intercalating dyes are used for real-time PCR investigations. Most of these are accessible in ready-to-use, mastermix formulae. Our goal was to choose the best dye for excitation of the labelled probes. The tested dyes were LCGreen "LightCycler" 480 High Resolution Melting Master" (Roche Diagnostic GmbH, Mannheim, Germany); SybrGreen "LightCycler" 480 DNA Master SYBR Green I", (Roche); "IQ ${ }^{\mathrm{m}} \mathrm{SYBR}^{\circ}$ Green Supermix" (Bio-Rad Laboratries, Inc., Hercules, CA, USA); "Maxima" SYBR Green qPCR Master Mix no ROX" (Fermentas, Vilnius, Lithuania); and EvaGreen ("LC-FastStart DNA Master Hybridization Probes" (Roche) combined with EvaGreen dye (Biotium Inc., Hayward, CA, USA) and "Sso Fast ${ }^{\text {tix }}$ EvaGreen Supermix" (BioRad). All mastermixes were used according to the manufacturer's instructions.

\section{PCR conditions}

PCR was performed using a LightCycler real-time PCR instrument (Roche). The reaction volume of $10 \mu \mathrm{L}$ contained $1 \mu \mathrm{L}$ of DNA (with a final concentration of $\sim 10 \mathrm{ng} / \mu \mathrm{L}), 1 \mu \mathrm{M}$ of each of the primers, $0.7 \mu \mathrm{M}$ of each of the probes, an appropriate amount of mastermix, and $0.2 \mathrm{mM}$ BSA (in the cases of the Fermentas and BioRad mastermixes).

The PCR conditions were as follows: initial denaturation at $95^{\circ} \mathrm{C}$ for $600 \mathrm{~s}$, followed by 40 cycles of denaturation $\left(95^{\circ} \mathrm{C}\right.$ for $\left.0 \mathrm{~s}, 20^{\circ} \mathrm{C} / \mathrm{s}\right)$, annealing $\left(55^{\circ} \mathrm{C}\right.$ for $\left.15 \mathrm{~s}, 20^{\circ} \mathrm{C} / \mathrm{s}\right)$, and extension $\left(72^{\circ} \mathrm{C}\right.$ for $\left.20 \mathrm{~s}, 2^{\circ} \mathrm{C} / \mathrm{s}\right)$. The emitted fluorescence was measured after the annealing steps. The melting-curve analysis procedure consisted of 1 cycle at $95^{\circ} \mathrm{C}$ for $10 \mathrm{~s}, 40^{\circ} \mathrm{C}$ for $120 \mathrm{~s}$, followed by an increase in the temperature to $95^{\circ} \mathrm{C}$ at $0.2^{\circ} \mathrm{C} / \mathrm{s}$. The fluorescence signal (F) was monitored continuously during the temperature ramp, and plotted against temperature (T).

\section{Data analysis}

The melting peaks were evaluated using the LightCycler Software V 3.5. The melting-peaks were determined through the manual $\mathrm{T}_{\mathrm{m}}$ option on the three detection channels (F1, F2 and F3).

The standard deviation (SD) of the melting-points was calculated from five parallel experiments. The fungal or bacterial samples were verified by gel electrophoresis on $1.5 \%$ agarose gel, with the help of a low-range DNA ladder.

The sensitivity of the multiplex PCR calculated from five dilutions of the bacterial suspension.

\section{Abbreviations \\ RT PCR: Real-time PCR; FRET: Fluorescence resonance energy transfer; LC: LightCycler; ICU: Intensive Care Unit; ITS: Internal transcribed spacer; ATCC: American Type Cell Culture; IFM: IFM Quality Services Pty Ltd; SzMC: Szeged Microbiological Collection; $T_{m}$ : Melting temperature; SD: Standard deviation; $T_{m} A$ : Melting peak of the amplicon; $T_{m} P$ : Melting peak of the probe.}

\section{Competing interests}

The authors declare that they have no competing interests.

\section{Authors' contributions}

ÁH: helped in the design, performed the experiments, analysed the data and wrote the manuscript. ZP: provided the clinical samples, helped in the analysis and interpretation of the data and revised the manuscript. EU: provided all the clinical bacterial samples and critiqued the manuscript. CsV: have made substantial contributions to concept and design, provided the fungal samples and revised the manuscript. FS: designed all the experiments, participated in the writing of the manuscript, revised the manuscript and gave final approval of the version to be published. All the authors have read and approved the final manuscript.

\section{Authors' information}

ÁH: Doctoral fellow in the Department of Medical Microbiology and Immunobiology, Faculty of Medicine, University of Szeged, Dóm tér 10, Szeged, Hungary, ZP: Chief of Medicine on the Department of Anaesthesiology and Intensive Therapy, Faculty of Medicine, University of Szeged, Semmelweis u. 6, Szeged, Hungary, EU: Chair of the Institute of Clinical Microbiology, Faculty of Medicine, University of Szeged, Semmelweis u. 6, Szeged, Hungary CsV: Chair of the Department of Microbiology, Faculty of Science and Informatics, University of Szeged, Közép fasor 52, Szeged, Hungary FS:Senior research fellow on the Department of Medical Microbiology and Immunobiology, Faculty of Medicine, University of Szeged, Dóm tér 10, Szeged, Hungary,

\section{Acknowledgements}

This research was supported by the European Union and the State of Hungary, co-financed by the European Social Fund in the framework of TÁMOP 4.2.4. A/2-11-1-2012-0001 'National Excellence Program'. This publication is supported financially by the project named "TÁMOP-4.2.2. A-11/1/ KONV-2012-0035 - Creating the Center of Excellence at the University of Szeged" is supported by the European Union and co-financed by the European Regional Fund. The authors would like to acknowledge Dr. Gabriella Spengler and Prof. Yvette Mándi whose suggestions helped to improve the final version of the manuscript. 


\section{Author details}

${ }^{1}$ Department of Medical Microbiology and Immunobiology, Faculty of Medicine, University of Szeged, Dóm tér 10, Szeged H-6720, Hungary. ${ }^{2}$ Department of Anaesthesiology and Intensive Therapy, Faculty of Medicine, University of Szeged, Semmelweis u. 6, Szeged, Hungary. ${ }^{3}$ Institute of Clinical Microbiology, Faculty of Medicine, University of Szeged, Semmelweis u. 6, Szeged, Hungary. ${ }^{4}$ Department of Microbiology, Faculty of Science and Informatics, University of Szeged, Közép fasor 52, Szeged, Hungary.

Received: 28 January 2013 Accepted: 13 December 2013

Published: 23 December 2013

\section{References}

1. Danai PA, Moss M, Mannino DM, Martin GS: The epidemiology of sepsis in patients with malignancy. Chest 2006, 129:1432-1440.

2. Martin GS, Mannino DM, Eaton S, Moss M: The epidemiology of sepsis in the United States from 1979 through 2000. N Engl J Med 2003, 348:1546-1554.

3. Klotz SA, Chasin BS, Powell B, Gaur NK, Lipke PN: Polymicrobial bloodstream infections involving Candida species: analysis of patients and review of the literature. Diagn Microbiol Infect Dis 2007, 59:401-406.

4. Vallés J, Rello J, Ochagavía A, Garnacho J, Alcalá MA: Community-acquired bloodstream infection in critically ill adult patients: impact of shock and inappropriate antibiotic therapy on survival. Chest 2003, 123:1615-1624.

5. Kumar A, Ellis P, Arabi Y, Roberts D, Light B, Parrillo JE, Dodek P, Wood G, Kumar A, Simon D, Peters C, Ahsan M, Chateau D, Cooperative Antimicrobial Therapy of Septic Shock Database Researc Group: Initiation of inappropriate antimicrobial therapy results in a fivefold reduction of survival in human septic shock. Chest 2009, 136:1237-1248.

6. Leggieri N, Rida A, François P, Schrenzel J: Molecular diagnosis of bloodstream infections: planning to (physically) reach the bedside. Curr Opin Infect Dis 2010, 23:311-319.

7. Carroll NM, Jaeger EE, Choudhury S, Dunlop AA, Matheson MM, Adamson P, Okhravi N, Lightman S: Detection of and discrimination between Gram-positive and Gram-negative bacteria in intraocular samples by using nested PCR. J Clin Microbiol 2000, 38:1753-1757.

8. Didenko W: DNA Probes Using Fluorescence Resonance Energy Transfer (FRET): Designs and Applications. Biotechniques 2001, 31:1106-1121.

9. Klaschik S, Lehmann LE, Raadts A, Book M, Hoeft A, Stuber F: Real-time PCR for detection and differentiation of Gram-positive and Gram-negative bacteria. J Clin Microbiol 2002, 40:4304-4307.

10. Klaschik S, Lehmann LE, Raadts A, Book M, Gebel J, Hoeft A, Stuber F: Detection and differentiation of in vitro-spiked bacteria by real-time PCR and melting-curve analysis. J Clin Microbio/ 2004, 42:512-517.

11. Schoch CL, Seifert KA, Huhndorf S, Robert V, Spouge JL, Levesque CA, Chen W, Fungal Barcoding Consortium; Fungal Barcoding Consortium Author List: Nuclear ribosomal internal transcribed spacer (ITS) region as a universal DNA barcode marker for Fungi. Proc Natl Acad Sci U S A 2012, 109:6241-6246.

12. Somogyvari F, Serly J, Doczi I, Nagy E: Molecular differentiation of most frequent Candida species causing blood-stream infection. Mycoses 2005 2:S198.

13. Zhou L, Myers AN, Vandersteen JG, Wang L, Wittwer CT: Closed-tube genotyping with unlabeled oligonucleotide probes and a saturating DNA dye. Clin Chem 2004, 50:1328-1335.

14. Lind K, Ståhlberg A, Zoric N, Kubista M: Combining sequence-specific probes and DNA binding dyes in real-time PCR for specific nucleic acid quantification and melting curve analysis. Biotechniques 2006, 40:315-319.

15. Kilic A, Basustaoglu AC: Double triplex real-time PCR assay for simultaneous detection of Staphylococcus aureus, Staphylococcus epidermidis, Staphylococcus hominis, and Staphylococcus haemolyticus and determination of their methicillin resistance directly from positive blood culture bottles. Res Microbiol 2011, 162:1060-1066.

16. Maheux AF, Bissonnette $L$, Boissinot $M$, Bernier JL, Huppé $V$, Bérubé $E$, Boudreau DK, Picard FJ, Huletsky A, Bergeron MG: Method for rapid and sensitive detection of Enterococcus sp. and Enterococcus faecalis/ faeciumcells in potable water samples. Water Res 2011, 45:2342-2354.

17. Bo SN, Bo J, Ning YZ, Zhao Y, Lu XL, Yang JY, Zhu X, Yao GQ: Relationship between time to positivity of blood culture with clinical characteristics and hospital mortality in patients with Escherichia coli bacteremia. Chin Med J (Engl) 2011, 3:330-334
18. Gutzmer R, Mommert S, Küttler U, Werfel T, Kapp A: Rapid identification and differentiation of fungal DNA in dermatological specimens by LightCylerPCR. J Med Microbiol 2004, 53:1207-1214.

19. Somogyvari F, Doczi I, Serly J, Suhail A, Nagy E: Rapid discrimination between Candida albicans and Candida dubliniensis by using real-time PCR. Diagn Microbiol Infect Dis 2007, 58:367-369.

20. Somogyvari F, Horvath A, Serly J, Majoros H, Vagvolgyi C, Peto Z: Detection of Invasive Fungal Pathogens by Real-time PCR and High-resolution Melting Analysis. In Vivo 2012, 26:979-983.

21. Ferrer C, Colom F, Frasés S, Mulet E, Abad JL, Alió JL: Detection and identification of fungal pathogens by PCR and by ITS2 and $5.8 \mathrm{~S}$ ribosomal DNA typing in ocular infections. J Clin Microbio/ 2001, 39:2873-2879.

22. Turenne C, Sanche SE, Hoban DJ, Karlowsky JA, Kabani AM: Rapid identification of fungi by using the ITS2 genetic region and an automated fluorescent capillary electrophoresis system. J Clin Microbiol 1999, 37:1846-1851.

23. Khan Z, Mustafa AS, Alam FF: Real-time LightCycler polymerase chain reaction and melting temperature analysis for identification of clinically important Candida spp. J Microbiol Immunol Infect 2009, 42:190-195.

24. Lehmann LE, Alvarez J, Hunfeld KP, Goglio A, Kost GJ, Louie RF, Raglio A, Regueiro BJ, Wissing $H$, Stüber F: Potential clinical utility of polymerase chain reaction in microbiological testing for sepsis. Crit Care Med 2009, 37:3085-3090

25. Bouza E, Sousa D, Rodríguez-Créixems M, Lechuz JG, Muñoz P: Is the volume of blood cultured still a significant factor in the diagnosis of bloodstream infections? J Clin Microbiol 2007, 45:2765-2769.

26. Waldeisen JR, Wang T, Mitra D, Lee LP: A real-time PCR antibiogram for drug-resistant sepsis. PLoS One 2011, 6:e28528.

27. von Lilienfeld-Toal M, Lehmann LE, Raadts AD, Hahn-Ast C, Orlopp KS: Utility of a commercially available multiplex real-time PCR assay to detect bacterial and fungal pathogens in febrile neutropenia. J Clin Microbiol 2009, 47:2405-2410.

28. Vince A, Lepej SZ, Barsic B, Dusek D, Mitrovic Z, Serventi-Seiwerth R, Labar B: LightCycler SeptiFast assay as a tool for the rapid diagnosis of sepsis in patients during antimicrobial therapy. J Med Microbiol 2008, 57:1306-1307.

29. Wallet F, Nseir S, Baumann L, Herwegh S, Sendid B: Preliminary clinical study using a multiplex real-time PCR test for the detection of bacterial and fungal DNA directly in blood. Clin Microbiol Infect 2010, 16:774-779.

30. Bauer M, Reinhart K: Molecular diagnostics of sepsis - Where are we today? Int J Med Microbiol 2010, 300:411-413.

31. Tissari P, Zumla A, Tarkka E, Mero S, Savolainen L, Vaara M, Aittakorpi A, Laakso S, Lindfors M, Piiparinen H, Maki M, Carder C, Huggett J, Gant V: Accurate and rapid identification of bacterial species from positive blood cultures with a DNA based microarray platform: an observational study. Lancet 2010, 375:224-230.

32. Cleven BEE, Palka-Santini M, Gielen J, Meembor S, Krönke M, Krut O: Identification and characterization of bacterial pathogens causing bloodstream infections by DNA microarray. J Clin Microbiol 2006, 44:2389-2397.

33. Lucignano B, Ranno S, Liesenfeld O, Pizzorno B, Putignani L, Bernaschi P, Menichella D: Multiplex PCR allows rapid and accurate diagnosis of bloodstream infections in newborns and children with suspected sepsis. J Clin Microbiol 2011, 49:2252-2258.

34. Lim CS, Tung CH, Rosli R, Chong PP: An alternative Candida spp. cell wall disruption method using a basic sorbitol lysis buffer and glass beads. J Microbiol Methods 2008, 75:576-578.

35. Miller SA, Dykes DD, Polesky HF: A simple salting out procedure for extracting DNA from human nucleated cells. Nucleic Acids Res 1988, 16:1215-1218.

36. Liu D, Coloe S, Baird R, Pederson J: Rapid mini-preparation of fungal DNA for PCR. J Clin Microbiol 2000, 38:471.

37. Lott TJ, Kuykendall RJ, Reiss E: Nucleotide sequence analysis of the $5.8 \mathrm{~S}$ rDNA and adjacent ITS2 region of Candida albicans and related species. Yeast 1993, 9:1199-1206.

doi:10.1186/1471-2180-13-300

Cite this article as: Horváth et al:: A novel, multiplex, real-time PCR-based approach for the detection of the commonly occurring pathogenic fungi and bacteria. BMC Microbiology 2013 13:300. 